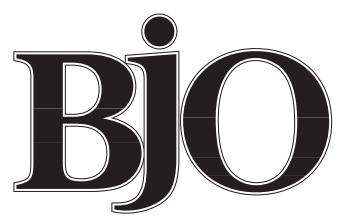

British Journal of Ophthalmology

\title{
Editorial
}

\section{Importance of early diagnosis of retinoblastoma}

All physicians should be aware of the early symptoms and signs of cancer. Depending on the type of cancer, failure to make an early diagnosis can pose a threat to the involved organ and, more importantly, to the patient's life. These principles are particularly true with regard to retinoblastoma, a disease that affects infants and young children. Failure to recognise retinoblastoma at an early stage can lead to blindness, cosmetic deformities, and, in advanced cases, even death. ${ }^{1-3}$

In this issue of the $B \mathcal{B O}$, Goddard and colleagues report their observations on delayed diagnosis of retinoblastoma and its effects on type of treatment and outcome ( $p$ 1320). They found that there was an increased risk of delayed diagnosis in younger children, in children who presented with strabismus rather than leucocoria, and in those who were evaluated initially by a health visitor rather than a medical physician. This delay in diagnosis appeared to increase the risk of local tumour invasion. Fortunately, there were no deaths in this group of patients.

Many years ago, enucleation was the only acceptable treatment for retinoblastoma. Although enucleation was probably a life saving procedure in many cases, it eliminated any chance of vision in the affected eye and it was associated with the usual problems of an anophthalmic socket, including cosmetic considerations, dry eye, and infection. Later, the introduction of external beam radiation therapy (EBRT) allowed salvage of many eyes, some with useful vision. However, a number of potentially serious problems were subsequently recognised to be associated with EBRT. Firstly, it frequently led to dry eye symptoms, radiation cataract, and radiation retinopathy. Secondly, it often caused facial cosmetic deformity secondary to atrophy of soft tissue in the orbit and temporal fossa. Thirdly, and most importantly, it was found to spawn a number of malignant secondary neoplasms in the field of irradiation. ${ }^{4}$

Many of the problems associated with enucleation and EBRT were subsequently alleviated by use of radioactive plaque brachytherapy, ${ }^{125}$ laser photocoagulation, ${ }^{126}$ and cryotherapy. ${ }^{127}$ However, these methods were mainly appropriate for small or recurrent tumours, often in eyes that had already undergone external beam irradiation.

More recently, techniques of chemoreduction and chemothermotherapy have achieved popularity in the management of selected retinoblastomas. Chemoreduction is a method of treating a tumour with chemotherapy with the goal of reducing tumour size, so that a more conservative method of treatment can be employed. ${ }^{8}{ }^{9}$ Hence, eyes that would have required enucleation or EBRT in the past are managed with chemoreduction combined with thermotherapy, plaque brachytherapy, or cryotherapy. Chemothermotherapy uses chemotherapy synergistically with heat, delivered with a modified diode laser system. This results in a smaller retinal scar than occurs with laser photocoagulation or cryotherapy. ${ }^{10}$

Early results of these new treatment modalities suggest that retinoblastoma, if diagnosed early enough, can be managed without enucleation or any form of irradiation. Thus, the importance of early diagnosis becomes obvious. It is apparent that if all retinoblastomas could be recognised either in utero or shortly after birth, most of them could be treated promptly by the aforementioned methods, thus saving the child's life and salvaging useful vision. Goddard and associates have found that there is often a delay in diagnosis and they alluded to the difficulties in making an early diagnosis of retinoblastoma. However, the method of obtaining earlier diagnosis remains a dilemma.

Ideally, it would be possible to alleviate the problem of late diagnosis by having an eye screening programme for all children shortly after birth, using indirect ophthalmoscopy by a qualified ophthalmologist. However, implementation of such a screening programme for poorly cooperative infants would be difficult and probably not economically feasible, particularly when one considers that retinoblastoma is a rare malady.

It seems, therefore, that the next best chance of alleviating the problem of late diagnosis of retinoblastoma, would be through education of the healthcare personnel who would possibly be first to see a child with retinoblastoma. There is no simple way of achieving this goal. However, many ophthalmologists do have the opportunity to teach other physicians or citizens in their community about ocular diseases. The inclusion of a little about retinoblastoma in such efforts could possibly facilitate its earlier recognition.

Since ocular oncologists ultimately evaluate many patients with retinoblastoma, it should be the responsibility of ocular oncologists to review periodically the clinical features of retinoblastoma with paediatric ophthalmologists, retinal specialists, and general ophthalmologists. Using similar methods, local ophthalmologists should reach paediatricians, optometrists, and general physicians regarding early signs of retinoblastoma. Such education can be done either by lectures or distribution of pertinent literature. Literature oriented to laymen could be exhibited in paediatricians' waiting rooms for parents to read. The lectures and distributed material do not need to be 
oriented entirely to retinoblastoma, but should include retinoblastoma as part of their overall format. It should be pointed out that any child with an abnormal pupillary reflex, strabismus, ocular redness, or other unusual ocular signs, should be referred promptly to an ophthalmologist or an ocular oncologist. Furthermore, it would be desirable if local healthcare personnel could encourage parents to have their children examined by an eye care physician at an early age, particularly if the eyes seem abnormal.

In summary, most retinoblastomas will continue to be quite advanced at the time of diagnosis and enucleation or external beam irradiation will remain the only therapeutic options in such cases. However, we have recently observed a decrease in the necessity of enucleation ${ }^{11}$ and we expect it to further decrease with the judicial use of chemoreduction and chemothermotherapy. But, earlier diagnosis is still an attainable goal. It may not be feasible to institute widespread, comprehensive retinoblastoma screening programmes for all infants and young children. However, if ophthalmologists can include early recognition of retinoblastoma in their teaching efforts to reach other healthcare personnel, then there is a chance that more cases will be recognised earlier, resulting in implementation of more conservative therapeutic modalities. This, in turn, should lead to even lower mortality and preservation of visual function in eyes that otherwise would have required enucleation or external beam irradiation. If this goal can be achieved, many children with retinoblastoma may retain better vision and enjoy a better quality of life.

JERRY A SHIELDS

Ocular Oncology Service, Wills Eye Hospital, Philadelphia, PA 19107, USA

1 Shields JA, Shields CL. Management and prognosis or retinoblastoma. In: Shields JA, Shields CL, eds. Intraocular tumors. A text and atlas. Philadelphia: WB Saunders, 1992:377-91.

2 Shields JA, Shields CL. Retinoblastoma. In: Shields JA, Shields CL, eds. Atlas of intraocular tumors. Philadelphia: Lippincott, Williams and Wilkins, 1999:208-9.

3 Sanders BM, Draper GJ, Kingston JE. Retinoblastoma in Great Britain 1969-1980: incidence, treatment, and survival. Br f Ophthalmol 1988;72:

4 Draper GJ, Sanders BM, Kingston JE. Second primary neoplasms in patients with retinoblastoma. Br 7 Cancer 1986;53:661-71.

5 Shields CL, Minelli S, Shields JA, et al. Plaque radiotherapy for retinoblastoma. Use as a primary and secondary treatment. Ophthalmology 1993;100: $216-24$

6 Shields JA, Parsons H, Shields CL, et al. The role of photocoagulation in the management of retinoblastoma. Arch Ophthalmol 1990;108:205-8.

7 Shields JA, Parsons H, Shields CL, et al. The role of cryotherapy in the management of retinoblastoma. Am f Ophthalmol 1989;108:260-4.

8 Shields CL, De Potter P, Himmelstein B, et al. Chemoreduction in the initial management of intraocular retinoblastoma. Arch Ophthalmol 1996;114: $1330-8$.

9 Kingston JE, Hungerford JL, Madreperla SA, et al. Results of combined chemotherapy and radiotherapy for advanced intraocular retinoblastoma. Arch Ophthalmol 1996;114:1339-47.

10 Shields JA, Shields CL, De Potter P, et al. Bilateral macular retinoblastoma managed by chemoreduction and chemothermotherapy. Arch Ophthalmol managed by chem

11 Shields JA, Shields CL, Sivalingam V. Decreasing frequency of enucleation in patients with retinoblastoma. Am f Ophthalmol 1989;108:185-8.

Applications are invited for the post of:

\section{EDITOR \\ British Fournal of Ophthalmology}

Specialists in any branch of ophthalmology are invited to apply for the post of Editor. Please send a letter of application, a curriculum vitae, and a short statement about the strengths and weaknesses of $\mathrm{BFO}$, and your proposed editorial policy. Full editorial support will be provided and it is envisaged that the editor will need to devote about one day a week to the journal. BfO is international and we seek applicants worldwide. Applications from ophthalmologists and joint applications from two or more candidates wishing to act as co-editors will be welcomed.

Closing date is 10 December 1999. Interviews will be held in January 2000 to enable the successful candidate to take up the post in the first half of 2000 .

Details of the post can be discussed with Alex Williamson, to whom applications should be sent. A job description is available on request.

Mrs Alex Williamson, BMJ Publishing Group, BMA House, Tavistock Square, London WC1H 9JR. Tel: +44 171383 6169; Fax: +44 171383 6668; email: awilliamson@bmigroup.com 